\title{
TYRE WEAR DURING BRAKING
}

\author{
Dr Nenad Janićijević* \\ University of Belgrade, Faculty of Mechanical Engineering, Belgrade, Serbia
}

Apart from the other factors, a tyre wear is primarily dependent on energy absorbed within the tyre grip area during braking or during vehicle acceleration. This paper shows set of derived equations that can be used to calculate the amount of absorbed energy within brakes, as well as within the tyre grip area for various typical cases and conditions occurring during braking.

Key words: Energy balance, Braking, Vehicle, Tyre, Wear

\section{INTRODUCTION}

A contact between a vehicle and a surface on which it travels is maintained through its wheels i.e. tyres $[04,08]$. Because of that, the characteristics of tyres and their contact area with the surface and the physical processes that are developing there all have a major impact on vehicle's handling and tyre wear $[01,02]$.Tyre wear is influenced by a variety of factors, among others being a driving style, which is often neglected. A driving style is determined by the three major factors, firstly the way a vehicle is accelerated from the standing position, secondly the intensity of braking and finally, the velocity during negotiating road bends and curves. This analysis focuses on influence of the former two driving style factors, since during the intense acceleration from the standstill position (especially in cases of highly powered vehicles) and during the intense braking, a significant wheel skid occurs. This has a direct (negative) influence on vehicle stability and tyre wear. The ASR and ABS on modern vehicles are nowadays primarily fitted to maintain vehicle stability as well as steerability and they do also reduce tyre wear. Since the intense acceleration from the standstill has the same effect on tyre wear as the intense braking [05, 06], only the analysis of tyre wear during braking is performed here. The total kinetic energy of a braked vehicle is absorbed within brakes and also within the tyre grip area, so the magnitude of tyre wear is represented by a quantity of energy absorbed in that contact area.

\section{ENERGY BALANCE DURING VEHICLE BRAKING}

In the beginning of braking, the total kinetic energy of the vehicle consists of two components: a kinetic energy of masses in translation (total mass of the loaded vehicle) and a kinetic energy of masses that rotate (either during disengagement of the clutch or when a gearbox is in a neutral position - these would be gears, shafts, brake discs and wheels) [07].

Kinetic energy of masses that rotate is expressed through the coefficient of rotating masses and the kinetic energy of the vehicle is therefore:

$E_{k v}=\frac{M V_{0}^{2}}{2}(1+\sigma)$

where:

$M$ - mass of the loaded vehicle,

$V_{o}$-initial velocity of the vehicle (velocity at which braking starts),

$\sigma$-rotational mass coefficient.

During braking (while the clutch is disengaged), a kinetic energy of the vehicle is converted into friction within the brakes, resistance of an air drag, friction within the transmission, friction of a rolling resistance and what is of prime importance for this analysis, friction within the tyre grip area. Therefore, the vehicle braking energy balance can be described by the following general equation [03]:

$E_{k v}=E_{t k}+E_{v}+E_{t r}+E_{f}+E_{i}$

where:

$E_{k v}$ - kinetic energy of the vehicle before the start of braking,

$E_{t k}$ - energy of friction within the brakes,

$E_{v}$ - drag resistance energy,

$E_{t r}$ - energy of friction within the transmission,

$E_{f}$ - rolling resistance energy,

$E_{\lambda}$ - energy of friction within the tyre grip area.

When fully derived, the equation above becomes: 


$$
\begin{aligned}
\frac{M V_{0}^{2}}{2}(1+\sigma) & =\sum_{i=1}^{n} \int_{0}^{t_{k}} M_{k i} \omega_{i} d t+\int_{0}^{t_{k}} M_{r} \omega d t+ \\
& +C \int_{0}^{s_{k}} V^{2} d s+M_{v} g f s_{k}+\sum_{i=1}^{n} \int_{0}^{t_{k}} F_{k i} \lambda_{i} V d t
\end{aligned}
$$

where:

$n$ - number of braked wheels on the vehicle,

$M_{k i}$ - brake torque in brakes,

$\omega_{i}$ - angular speed of braked wheels,

$t_{k}$ - total braking time,

$M_{r}$ - frictional torque in the transmission (relative to the wheels)

$V$ - instantaneous (variable) velocity of the vehicle during braking,

$V_{0}$ - initial velocity of the vehicle (velocity at which the braking starts),

$s$ - distance travelled during the time $t$,

$s_{k}$ - distance travelled during braking,

$M_{v}$ - mass of the vehicle,

$f$ - rolling resistance coefficient,

$F_{k i}$ - braking forces (in the tyre grip area),

$\lambda_{i}$ - skid coefficient between the tyre and

the surface,

$c$ - drag coefficient.

During the sudden intense braking when all wheels lock, the equation (3) assumes the following form:

$$
\frac{M V_{0}^{2}}{2}=c \int_{0}^{s_{k}} V^{2} d s+F_{k u} s_{k}
$$

where:

$F_{f u}$ - total brake force in the tyre grip area,

$s_{k}$ - distance travelled during braking.

From the equation (4), the amount of energy that gets absorbed in the tyre grip area can be defined by the following equation:

$$
E_{\lambda}=\frac{M V_{0}^{2}}{2}-c \int_{0}^{s_{k}} V^{2} d s
$$

Since vehicle velocity during such braking gets rapidly reduced, the total amount of the second part of the right hand side of the equation becomes by a magnitude smaller than the first part and so it can be neglected. Hence, the vast majority of vehicle kinetic energy gets converted into frictional heat in the tyre grip area, heating up the portion of the tyre in contact with the surface and causing a circumferentially uneven tyre wear.

According to the equation (5), wear of tyres is directly proportional to the amount of energy absorbed in the tyre grip area and so now it is of interest to analyze an energy balance of braked wheels during different braking conditions.

\section{BRAKED WHEELS ENERGY BALANCE}

This balance depends on position of wheels in the vehicle (front or rear axle, for example), braking conditions and adhesion conditions in the tyre grip area. In terms of braking conditions, the intensity, speed of brake activation and frequency of activation are all important.

Determination of the amount of energy absorbed in brakes and in the tyre grip area will be now performed for the following four characteristic cases:

- Pre-braking, i.e. gradual increase of the brake torque until a certain value is reached that does not block the wheels;

- Gradual increase of the brake torque until such a value is reached, which fully utilizes a maximum available coefficient of adhesion between the tyre and the surface;

- Sudden braking with utilization of a maximum available coefficient of adhesion between the tyre and the surface;

- Sudden braking with quick occurrence of wheel locking.

Complete process of deriving the equations that describe the absorbed energy within the brakes and within the tyre grip area are available in this author's work referenced under [01]. Therefore only the final equations are shown and discussed here.

\section{Pre-braking}

Energy absorbed within a brake is determined by:

$E_{k}=\frac{M_{k z} t_{k}\left(\omega_{0}+2 \omega_{z}\right)}{6}$

Energy absorbed in the tyre grip area is:

$$
\begin{aligned}
E_{\lambda 1}= & \frac{M_{k z} \omega_{0} t_{k}}{2 \lambda_{x}^{2}}\left[\lambda_{x}^{2}+2 \lambda_{x}-3+2 \ln t_{k}\left(1-\lambda_{x}\right)\right]- \\
& -\frac{M_{k z}\left(\omega_{0}-\omega_{z}\right) t_{k}}{6 \lambda_{x}^{3}}\left[1-6 \lambda_{x}-3 \lambda_{x}^{2}-2 \lambda_{x}^{3}-\right. \\
& \left.-6 \ln t_{k}\left(1-\lambda_{x}\right)\right]+\frac{J\left(\omega_{0}-\omega_{z}\right)^{2}}{2 \lambda_{x}^{2}}\left[3 \lambda_{x}-3+\right.
\end{aligned}
$$

Journal of Applied Engineering Science 13(2015)3, 321 


$$
\begin{aligned}
& \left.+2 \ln t_{k}\left(1-\lambda_{x}\right)\right]-\frac{J \omega_{0}\left(\omega_{0}-\omega_{z}\right)}{\lambda_{x}}\left[1-\lambda_{x}-\right. \\
& \left.-\ln t_{k}\left(1-\lambda_{x}\right)\right],
\end{aligned}
$$

where:

$M_{k z}$ - the highest brake torque (achieved at the end of braking),

$t_{k}$ - braking time (until reaching $M k z$ ),

$\omega_{0}$ - initial angular speed of the wheel (at the

beginning of braking),

$\omega_{z}$ - final angular speed of the wheel (at the end of braking),

$\lambda_{x}$ - skidding at the end of braking,

$J$ - moment of inertia of all rotating masses from the clutch to the wheel.

From the above equation a very small amount of skid is absorbed in the tyre grip area, hence it the skid energy is also very small and so almost the entire amount of energy is being absorbed by the brake.

Gradual increase of the brake torque until such a value is reached, which fully utilises a maximum available coefficient of adhesion between the tyre and the surface

Energy absorbed in the brake is determined by:

$$
E_{t k}=\frac{M_{k o} t_{z}\left(\omega_{0}+2 \omega_{z}\right)}{6}+\frac{M_{k 0} \omega_{z}\left(t_{k}-t_{z}\right)}{2}
$$

Energy absorbed in the tyre grip area:

$$
E_{\lambda 2}=E_{\lambda 1}^{*}+\frac{M_{k 0} \lambda_{0} \omega_{z}\left(t_{k}-t_{z}\right)}{2\left(1-\lambda_{0}\right)}-\frac{J \lambda_{0} \omega_{z}^{2}}{2\left(1-\lambda_{0}\right)}
$$

where:

$M_{k 0}$ - a brake torque that dictates utilization of the available maximum adhesion coefficient,

$t_{z}$ - time until the brake torque reaches $M_{k 0}$,

$t_{k}$ - total braking time,

$E_{\lambda 1}{ }^{*}$ - is the same as $E_{\lambda 1}$ but instead of $\lambda_{x}$, the $\lambda_{0}$ is used (skid at $M_{k o}$ ) and also instead $t_{k^{\prime}}$, the $t_{z}$ is used,

$\lambda_{0}$ - skid at $M_{k 0}$,

$\omega_{z}$ - angular wheel speed when $M_{k 0}$ is reached.

Sudden braking with utilization of a maximum available coefficient of adhesion between the tyre and the surface
Energy absorbed within the brake:

$E_{k}=\frac{M_{k 0} \omega_{0} t_{k}}{2}$

Energy absorbed in the tyre grip area:

$E_{\lambda}=\frac{M_{k 0} \omega_{0} \lambda_{0} t_{k}}{2\left(1-\lambda_{0}\right)}-\frac{J \omega_{0}^{2} \lambda_{0}}{2\left(1-\lambda_{0}\right)}$

where:

$M_{k 0}=$ const. - brake torque,

$\lambda_{0}=$ const - skid at maximum adhesion coefficient.

By analyzing the equation (11) we can conclude that the amount of energy absorbed in the tyre grip area is larger than the amount of energy in the previous case, but it does not exceed $1015 \%$ of the total energy absorbed during braking.

\section{Sudden braking with quick occurrence of wheel locking}

During the first phase of braking before the wheel is locked, the energy absorbed in the brake is:

$E_{k}=\frac{M_{k 0} \omega_{o} t_{b}}{2}$

and the energy absorbed in the tyre grip area is determined by the equation (11) in which the $t_{k}$ is replaced by the $t_{b}$ (time from the start of braking until the maximum adhesion coefficient is utilized).

In the second phase of braking when the wheel is locked there is no absorption of energy in the brake because almost all of the energy is absorbed in the tyre grip area. That energy is determined by:

$$
E_{\lambda}=\frac{F_{k} V_{b}\left(t_{k}-t_{b}\right)}{2}
$$

where:

$F_{k}$ - brake force in the tyre grip area

$V_{b}$ - velocity at the moment when the wheel is locked.

The ratio of energy absorbed in the brake and in the tyre grip area depends on time tb. The shorter this time is, the smaller is the amount of energy absorbed in the brake and so the larger is the amount absorbed in the tyre grip area.

In cases of "panic braking" the time tb is very short and so all the energy is absorbed in the tyre grip area. 


\section{EXPERIMENTAL VALIDATION OF THE DERIVED EQUATION FOR THRID CASE OF BRAKING}

To verify the validity of the above derived equation for the amount of energy absorbed within the brake, an experimental testing of a passenger car brake for the third characteristic case (sudden braking with utilization of a maximum available coefficient of adhesion between the tyre and the surface) was performed on the laboratory test bed. A measured value of the absorbed kinetic energy amounted to $26026 \mathrm{Nm}$. A value calculated by using the respective equation was $26068 \mathrm{Nm}$, so the total error of calculation amounted to $0.2 \%$.

From the equations (10) and (11) that are related to this specific case of braking, it is obvious that:

$$
E_{\lambda}=\frac{\lambda_{0}}{1-\lambda_{0}}\left(E_{k}-\frac{J \omega_{0}^{2}}{2}\right)
$$

If the second, right hand side of the expression in the brackets is neglected as small:

$$
E_{\lambda}=\frac{\lambda_{0}}{1-\lambda_{0}} E_{k}
$$

From the above equation in case of braking when the available maximum adhesion coefficient is utilized with the skid coefficient of $\lambda_{0}=$ 0.2 , the energy absorbed in the tyre grip area would amount to $6506.5 \mathrm{Nm}$. This magnitude of energy would cause relatively large amount of tyre wear each time such braking is performed.

The typical skid coefficient during the intense braking of vehicles equipped with ABS may vary within limits of 0.15 to 0.5 , so the amount of the absorbed energy in the tyre grip area may be significantly larger.

\section{CONCLUSION}

During braking the kinetic energy is absorbed not only within the brakes but also in the tyre grip area. The distribution of those absorbed energies primarily depends on the way braking is performed. The amount of energy absorbed in the tyre grip area represents a measure of tyre wear.

Braking when the wheel is locked causes not only significant tyre wear but due to its circumferential unevenness, negatively affects the wheel balance. This case of the steering axle wheels has a major negative implication on vehicle steer-ability.

\section{REFERENCES}

1) Bakker, E., Nyborg, L., Pacejka, H., (1987) Tyre modelling for use in vehicle dynamics studies, SAE Technical Paper No. 870421.

2) Danon, G., (1988) Tyre adhesion during vehicle braking on a straight line (in Serbian) (PhD thesis), Belgrade: Faculty of Mechanical Engineering.

3) Janićijević, N., (1978) Braked wheel energy balance (in Serbian), Tehnika - Mašinstvo, 6/1978.

4) Janićijević, N., (1992) Automatic control in motor vehicles (in Serbian), Belgrade: Faculty of Mechanical Engineering.

5) Janićijević, N., Janković, D., Todorović, J., (1979) Motor vehicle design (in Serbian), Belgrade: Faculty of Mechanical Engineering.

6) Todorović, J., (1988) Braking of motor vehicles (in Serbian), Belgrade: Institute for Textbooks.

7) Todorović, J., Janićijević, N., Danon G., (1978) An investigation of dynamic versus steady-state braking, Proceedings of the 17th International Automobile Technical Congress FISITA 1978, Budapest.

8) Wong, J.Y., (2008) Theory of ground vehicles $\left(4^{\text {th }}\right.$ ed), New York: John Wiley \& Sons.

Paper sent to revision: 14.07.2015.

Paper ready for publication: 11.09.2015. 